\title{
Efficacy of Microwave Disinfection on Moist and Dry Dental Stone Casts with Different Irradiation Times
}

Mahmood Robati Anaraki ${ }^{1}$, Mohammad Taghi Akhi ${ }^{2}$, Tahereh Pirzadeh ${ }^{3}$, Elnaz Moslehifard ${ }^{1}$, Hamed Ghanati ${ }^{4}$, Amin Mosavi ${ }^{1 *}$,Azin Khorramdel ${ }^{5}$

1. Assistant Professor, Department of Prosthodontics, Faculty of Dentistry, Tabriz University of Medical Sciences, Tabriz, Iran

2. Associate Professor, Department of Microbiology, Faculty of Medicine, Tabriz University of Medical Sciences, Tabriz, Iran

3. Assistant Professor, Department of Microbiology, Faculty of Medicine, Tabriz University of Medical Sciences, Tabriz, Iran

4. Dental Student, Faculty of Dentistry, Tabriz University of Medical Sciences, Tabriz, Iran

5. Post Graduate Student, Department of Periodontics, Faculty of Dentistry, Tabriz University of Medical Sciences,

Tabriz, Iran

\begin{abstract}
Objectives: Dental practice contains the use of instruments and multiuse items that should be sterilized or disinfected properly. The aim of the current study was to investigate the effect of microwave irradiation on dental stone cast disinfection in moist and dry condition.

Materials and Methods: In this in vitro study, 76 stone casts were prepared by a sterile method. The casts were contaminated by Pseudomonas aeruginosa (ATCC 9027), Staphylococcus aureus (ATCC 6538), Enterococcus faecalis (ATCC 29212) as well as Candida albicans (ATCC 10231). Half the samples were dried for two hours and the other half was studied while still moist. The samples were irradiated by a household microwave at $600 \mathrm{~W}$ for 3,5 and 7 minutes. The microorganisms on the samples were extracted by immersion in tryptic soy broth and $.001 \mathrm{ml}$ of that was cultured in nutrient agar media, incubated overnight and counted and recorded as colony forming unit per milliliter (CFU/mL).

Results: The findings showed that microorganisms reduced to 4.87 logarithm of CFU/mL value on dental cast within seven minutes in comparison with positive control. Although microbial count reduction was observed as a result of exposure time increase, comparison between moist and dried samples showed no significant difference.

Conclusions: Seven-minute microwave irradiation at $600 \mathrm{~W}$ can effectively reduce the microbial load of dental stone casts. Wetting the casts does not seem to alter the efficacy of irradiation.
\end{abstract}

Keywords: Microwave Disinfection; Dental Stone Casts; Irradiation Times

\section{Corresponding author:}

Amin Mosavi

Department of Prosthodontics, Faculty of Dentistry, Tabriz University of Medical Sciences, Tabriz, Iran

Email: s_aminmosavi88@yahoo.com

Receive date: 2015-03-17| Accept date: 2014-04-15| Publish date: 2015-05-03

DOI: 10.7575/aiac.abcmed.15.03.03.07

\section{A.}




\section{Introduction}

In prosthodontics, many instruments and multiuse items are used that are not easily sterilized or disinfected, including prostheses, impressions and especially stone casts (1) All impressions, cast models and prostheses should be properly disinfected before being sent to the prosthetic laboratory as well as when they are sent back to the dental office. Dental casts could be contaminated while impressions are not disinfected by the technician or clinician or within fabricating or trying the prosthesis in laboratory and clinic for several times (1-3).

In order to reduce microbial contamination in the clinic and dental laboratory, several methods have been recommended. Any ideal disinfection method should preserve the physical and my mechanical properties of the materials in addition to bactericidal properties (4). The most used disinfection processes are chemical methods including immersion of the contaminated objects in sodium hypochlorite $(5,6)$. However, the efficacy of this method on microorganisms has not been able to fulfill all disinfection requirements $(4,7,8)$ and microbial transmission requires blockage by a practical, easy and effective disinfection or sterilization procedures. Moreover, in practice, contaminated gypsum casts are not possible to disinfect chemically. Therefore, microwave irradiation whose efficacy in sterilization of some contaminated objects has been revealed (9), is recommended as a practical physical sterilization method (10). In 1985, the technology was applied to the sterilization of dental appliances (11) and since then, it has been used in several studies for disinfecting acrylic resins (12) and removable dentures (13$15)$, due to its non-toxic, easy and repeatable procedure.

Since the microwave irradiation has been suggested for gypsum casts disinfecting, there are used in this context. Disinfection was reported by different irradiation techniques from one or two dry phase $(10,16-19)$ to irradiation of the cast immersed in water18, within different times from 319 to 1018 minutes and applying different energy levels from 650 to 900 watts (W) $(10,16-19)$. More studies have shown that applied lower levels of energy are safer for strength and accuracy of casts, than high levels and boiling the stone cast during the irradiation (17,19-23). Nevertheless, there are few studies about the efficiency of microwave disinfection with the safe qualification and it still is not known if the humidity of cast can enhance disinfection efficiency as has been shown in other studies (24-26) without immersion of the cast in water and boiling it by microwave.

In order to establish a practical protocol for disinfecting dental casts by microwave irradiation and considering the various reports in microwave disinfection efficiency, more research on this field seems to be necessary. Thus, the primarily purpose of the current study was to determine the effect of the household microwave irradiation at $600 \mathrm{~W}$ on disinfection of dental casts. Moreover, in this study the effects of the humidity on disinfection of dental stone casts were tested.

\section{Methods and Materials}

\section{Sample preparation}

Based on the pilot study, five samples were studied in each group of this laboratory study. By pouring silicon molds of full dental arch in a sterile method 76 stone casts were prepared, using type III dental stone (Elite Model, Zhermack, Italy) mixed with sterile distilled water in appropriate powder-water ratio according to manufacturer's instructions. All casts were cut transversely by a sterile plaster knife prior to final setting of the gypsum. The casts were removed from the molds 
approximately 45 minutes after pouring and broken into two equal halves and kept in sterile bags.

\section{Microbial contamination}

The samples were randomly divided into four groups and each group was separately immersed into a Tryptic Soy Broth (TSB) with $1.5 \times 108 \mathrm{CFU} / \mathrm{ml}$ of Pseudomonas aeruginosa (ATCC 9027), Staphylococcus aureus (ATCC 6538), Enterococcus faecalis (ATCC 29212) or Candida albicans (ATCC 10231) (all microorganisms purchased from Pasteur institute, Iran). Half of the samples in each group were randomly selected and were dried for two hour in incubator at $32^{\circ} \mathrm{C}$ before irradiation. The other half was irradiated while they were still moist. Eight moist samples and eight dried ones were not put through contamination and irradiation procedures and were used as negative controls.

\section{Microwave irradiation}

Both moist and dried samples of each test group were irradiated in a microwave oven (Samsung PG3210 China), set at $600 \mathrm{~W}$ and $2450 \mathrm{MHz}$ frequency, for 3, 5 or 7 minutes (Figure 1). From contaminated samples eight moist and eight dried ones were not irradiated and used as positive controls.

\section{Microbiological studies}

After irradiation procedure, all of the samples were individually immersed in $100 \mathrm{ml}$ TSB. The containers were carefully shacked for releasing of attached microorganism and 0.001 $\mathrm{ml}$ of the solution was separately transferred to 5 plates containing trypticase soy agar (TSA) by an agitator (Figure 2). The plates were incubated for 24 hours at $35^{\circ} \mathrm{C}$. Thereafter, colony forming unit per milliliter (CFU/mL) was counted.

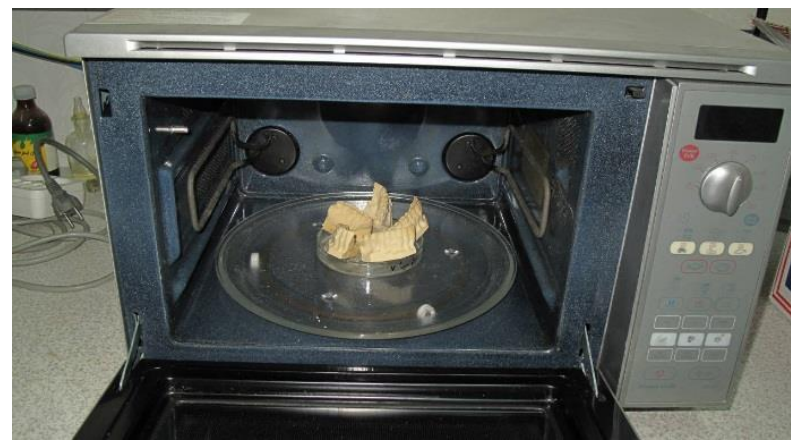

Figure 1: The contaminated casts were prepared to disinfecting in microwave oven

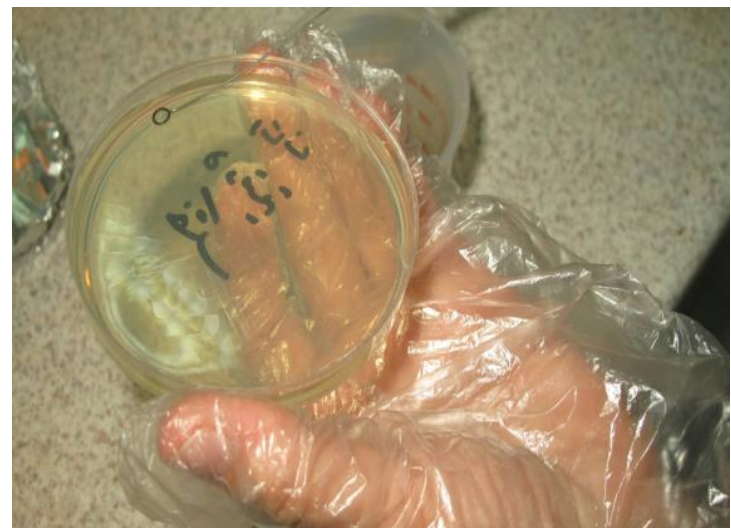

Figure 2: Looped end agitator was used to transfer $0.001 \mathrm{ml}$ of contaminated TSB for culturing to plated TSA 


\section{Statistical analysis}

One-way ANOVA with post-hoc LSD test was used to compare mean $\mathrm{CFU} / \mathrm{mL}$ in groups and Student's t-test was applied to determine difference between the moist and dried samples. The data analysis was performed using SPSS 15 software (Chicago, IL) and a P value of less than 0.05 was considered statistically significant.

\section{Results}

Comparing $\mathrm{CFU} / \mathrm{mL}$ values of the positive control grip[ with those of the case groups after microwave irradiation showed, 2.77 to 4.87 logarithm (log) reduction for $\mathrm{S}$. aureus in moist and C. albicans in dry samples with three- and seven-minute irradiation time respectively (Table 1).

\begin{tabular}{|c|c|c|c|c|c|c|}
\hline & & Viable cou & (CFU/mL) & & & \\
\hline & & & & & Log reduct & \\
\hline Sample grou & & Positive & Tes & nean) & & \\
\hline & & & 3 minutes & 7 minutes & 3 minutes & 7 minutes \\
\hline Dried casts & E faecalis & $9.32 \times 10^{6}$ & $3 \times 10^{3}$ & $8 \times 10^{2}$ & 3.49 & 4.07 \\
\hline & $\begin{array}{l}P \\
\text { aeruginosa }\end{array}$ & $1.26 \times 10^{7}$ & $9.8 \times 10^{3}$ & $1.2 \times 10^{3}$ & 3.11 & 4.02 \\
\hline & S aureus & $7.16 \times 10^{6}$ & $9 \times 10^{3}$ & $2 \times 10^{2}$ & 2.90 & 4.55 \\
\hline & Calbicans & $1.48 \times 10^{7}$ & $1.2 \times 10^{3}$ & $2 \times 10^{2}$ & 4.09 & 4.87 \\
\hline Moist casts & E faecalis & $9.32 \times 10^{6}$ & $3.4 \times 10^{3}$ & $8 \times 10^{2}$ & 3.44 & 4.07 \\
\hline & $\begin{array}{l}P \\
\text { aeruginosa }\end{array}$ & $1.26 \times 10^{7}$ & $1.26 \times 10^{4}$ & $1.2 \times 10^{3}$ & 3 & 4.02 \\
\hline & $S$ aureus & $7.16 \times 10^{6}$ & $1.22 \times 10^{4}$ & $2.6 \times 10^{3}$ & 2.77 & 3.44 \\
\hline & Calbicans & $1.48 \times 10^{7}$ & $2.2 \times 10^{3}$ & $8 \times 10^{2}$ & 3.83 & 4.27 \\
\hline
\end{tabular}

Table 1: Log reduction on viable counts after microwave irradiation of moist and dried casts in two irradiation times

Tables 2 and 3 demonstrate the microbial count reduction on moist and dried samples in different irradiation times. Although these results indicate that increasing the irradiation time would reduce the microbial count on dried samples, only $S$. aureus showed significant reduction and $P$. aeruginosa until $5 \mathrm{~min}$.
Moreover, the microbial count on moist samples was significantly reduced by increasing the exposure time from three to five minutes; except for $E$. faecalis that was significantly reduced after five minutes and $C$. albicans whose reduction was not significant by increasing the irradiation time. 


\section{Viable counts (CFU/mL)}

\begin{tabular}{|c|c|c|c|c|c|c|}
\hline \multirow{2}{*}{\multicolumn{2}{|c|}{ Sample groups }} & \multirow{3}{*}{$\begin{array}{l}\text { Positive } \\
\text { control }\end{array}$} & \multirow{2}{*}{\multicolumn{2}{|c|}{ Test (mean) }} & \multicolumn{2}{|c|}{ Log reduction } \\
\hline & & & & & \multirow[b]{2}{*}{3 minutes } & \multirow[b]{2}{*}{7 minutes } \\
\hline & & & 3 minutes & 7 minutes & & \\
\hline \multirow[t]{4}{*}{ Dried casts } & E faecalis & $9.32 \times 10^{6}$ & $3 \times 10^{3}$ & $8 \times 10^{2}$ & 3.49 & 4.07 \\
\hline & $\begin{array}{l}P \\
\text { aeruginosa }\end{array}$ & $1.26 \times 10^{7}$ & $9.8 \times 10^{3}$ & $1.2 \times 10^{3}$ & 3.11 & 4.02 \\
\hline & $S$ aureus & $7.16 \times 10^{6}$ & $9 \times 10^{3}$ & $2 \times 10^{2}$ & 2.90 & 4.55 \\
\hline & Calbicans & $1.48 \times 10^{7}$ & $1.2 \times 10^{3}$ & $2 \times 10^{2}$ & 4.09 & 4.87 \\
\hline \multirow[t]{4}{*}{ Moist casts } & E faecalis & $9.32 \times 10^{6}$ & $3.4 \times 10^{3}$ & $8 \times 10^{2}$ & 3.44 & 4.07 \\
\hline & $\begin{array}{l}P \\
\text { aeruginosa }\end{array}$ & $1.26 \times 10^{7}$ & $1.26 \times 10^{4}$ & $1.2 \times 10^{3}$ & 3 & 4.02 \\
\hline & $S$ aureus & $7.16 \times 10^{6}$ & $1.22 \times 10^{4}$ & $2.6 \times 10^{3}$ & 2.77 & 3.44 \\
\hline & Calbicans & $1.48 \times 10^{7}$ & $2.2 \times 10^{3}$ & $8 \times 10^{2}$ & 3.83 & 4.27 \\
\hline
\end{tabular}

Table 2: Effect of microwave irradiation on microbial colonies count on dried samples and moist samples at different irradiation times

\section{Viable counts (CFU/mL)}

\begin{tabular}{lllllll} 
Sample groups & \multicolumn{1}{c}{$\begin{array}{c}\text { Positive } \\
\text { control }\end{array}$} & \multicolumn{2}{c}{ Test (mean) } & & \\
& & & 3 minutes & 7 minutes & 3 minutes & 7 minutes \\
\hline Dried casts & E faecalis & $9.32 \times 10^{6}$ & $3 \times 10^{3}$ & $8 \times 10^{2}$ & 3.49 & 4.07 \\
& $\boldsymbol{P}$ & $1.26 \times 10^{7}$ & $9.8 \times 10^{3}$ & $1.2 \times 10^{3}$ & 3.11 & 4.02 \\
& aeruginosa & a & & & \\
& S aureus & $7.16 \times 10^{6}$ & $9 \times 10^{3}$ & $2 \times 10^{2}$ & 2.90 & 4.55 \\
& C albicans & $1.48 \times 10^{7}$ & $1.2 \times 10^{3}$ & $2 \times 10^{2}$ & 4.09 & 4.87 \\
Moist casts & E faecalis & $9.32 \times 10^{6}$ & $3.4 \times 10^{3}$ & $8 \times 10^{2}$ & 3.44 & 4.07 \\
& $\boldsymbol{P}$ & $1.26 \times 10^{7}$ & $1.26 \times 10^{4}$ & $1.2 \times 10^{3}$ & 3 & 4.02 \\
& aeruginosa & & & & & \\
& S aureus & $7.16 \times 10^{6}$ & $1.22 \times 10^{4}$ & $2.6 \times 10^{3}$ & 2.77 & 3.44 \\
& C albicans & $1.48 \times 10^{7}$ & $2.2 \times 10^{3}$ & $8 \times 10^{2}$ & 3.83 & 4.27 \\
\hline
\end{tabular}

Table 3: Post-hoc LSD test to compare dried and moist samples groups at different irradiation times

Comparison between moist and dried samples showed no significant difference (Table 4).

\section{Discussion}

The findings of this in vitro study showed that microorganisms were reduced to 4.87 logs on dental casts after irradiation in a microwave oven set at $600 \mathrm{~W}$ within seven minutes in comparison with a positive control group. 


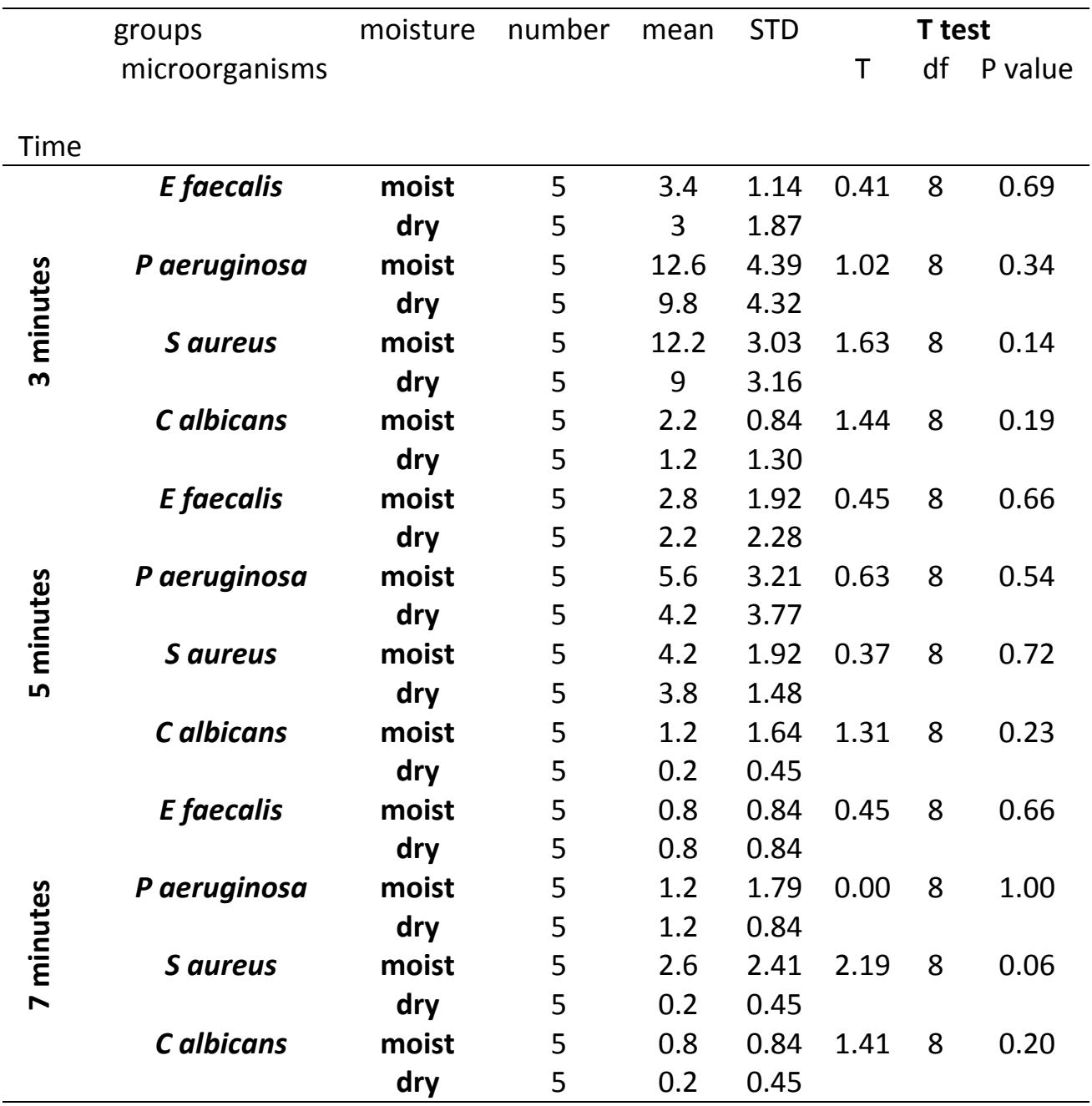

Table 4: Comparison between irradiation effect on moist and dried samples

These results are in agreement with previous studies in this area which explored the effect of microwave irradiation disinfection on stone casts $(9,17-19)$ Studies by Berg et al. on high level microwave disinfection of dental gypsum casts revealed 6 -log reduction of $\mathrm{CFU} / \mathrm{mL}$ of $S$. aureus and $P$. aeruginosa after five minutes of microwave irradiation in an ordinary household microwave oven set at 900 $\mathrm{W}$ and $2450 \mathrm{MHz}(9,17)$. One recent in vivo study on patients' dental casts showed $99 \%$ reduction of bacteria after three minutes of irradiation in a microwave oven set at $650 \mathrm{~W}$ (19).

Another study revealed that the cast could be disinfected after five minutes of irradiation at $850 \mathrm{~W}$ (18). In the latter study, the disinfection of the casts contaminated by Bacillus subtilis following 10 minutes of irradiation was considered as sterilization effect of this method (18).

The present study revealed almost the same log reduction of $\mathrm{CFU} / \mathrm{mL}$ using lower levels of microwave irradiation compared to a similar study with oral flora $(4.87$ vs. $5 \mathrm{log}$, respectively) (19). Further reduction of $\mathrm{CFU} / \mathrm{mL}$ in two other similar studies in comparison to our study could be due to higher levels of energy used and also different techniques applied $(9,17,18)$.

It has been shown that high levels of energy are harmful to stone casts from physical and mechanical aspects, as detrimental effect of microwave at $1450 \mathrm{~W}$ on surface hardness (23), 
$850 \mathrm{~W}$ on surface roughness and dimensional accuracy (18), and $700 \mathrm{~W}$ on surface hardness (24) have been documented. Using lower levels of energy has conserved dimensional accuracy in $490 \mathrm{~W}$ (22), compressive strength in $550 \mathrm{~W}$ (20), and enhanced diametric tensile strength in $600 \mathrm{~W}$ of energy (21).

Another finding of the current study was that the microbial count following irradiation did not show a significant difference between dried and moist casts. This is while a previous study showed a significantly higher microbial count reduction in casts immersed in water during irradiation (18). The latter study postulated that the irradiation would be more effective while there are water molecules around the microorganisms. We were not able to compare these findings; as in the current study, the mean weight of wet stone casts was only 10 grams more than that of dry ones. It seems that immersion of the cast in water and subjecting that to boiling during irradiation may have detrimental effects on the properties of the stone cast, and it might not be recommended as a safe technique for cast disinfection.

In the current study, the samples were contaminated by four strains as indicators of different types of pathogen microorganisms. Vegetative strains of Gram-positive nonsporogenic bacteria (S. aureus), Gram-negative resistant bacteria ( $P$. aeruginosa), Grampositive resistant bacteria (E. faecalis) and fungi (C. albicans) were recommended as indicator pathogens to increase the validity of disinfection procedures $(9,12,26)$.

The results of this study showed that $P$. aeroginosa and $S$. aureus are more resistant than two other tested microorganisms after three minutes while after seven minutes $E$. faecalis was the most resistant microorganism. These results are comparable with the study of Najdovski et al. that evaluated the killing activity of microwaves of $325 \mathrm{~W}, 650 \mathrm{~W}$ and $1400 \mathrm{~W}$ power on same bacterial strains. In their study, $P$. aeroginosa and $S$. aureus where killed after five minutes of irradiation at $350 \mathrm{~W}$ while $E$. faecalis was killed at $650 \mathrm{~W}$ after same exposure time (26).

As a result, effective reduction of microbial and fungal count can be achieved quickly and repeatedly by microwave disinfection. Although more studies are needed to evaluate other qualification of microwave treatment that enhance the efficacy in disinfection without detrimental effects on physical and mechanical properties of the stone cast.

\section{Conclusions}

Seven- minute microwave irradiation at 600 $W$ can effectively reduce the microbial load of dental casts. Lower irradiation times may not effectively reduce all bacterial contamination.

\section{Acknowledgments}

This study was supported by Research Vice Chancellor of Tabriz University of Medical Sciences. We are highly grateful for this support.

\section{References}

1. Mitchell DL, Hariri NM, Duncanson MG, Jacobsen NL, McCallum RE. Quantitative study of bacterial colonization of dental casts. The Journal of prosthetic dentistry. 1997;78(5):518-21.

2. Leung RL, Schonfeld SE. Gypsum casts as a potential source of microbial cross-contamination. J Prosthet Dent. 1983;49(2):210-1. 
3. Chassot ALC, PoisI MIP, Samuel SMW. In vivo and in vitro evaluation of the efficacy of a peracetic acid-based disinfectant for decontamination of acrylic resins. Braz Dent J. 2006;17(2):117.

4. Wu G, Yu X, Gu Z. Ultrasonically nebulised electrolysed oxidising water: a promising new infection control programme for impressions, metals and gypsum casts used in dental hospitals. J Hosp Infect. 2008;68(4):348-54.

5. Taylor RL, Wright PS, Maryan C. Disinfection procedures: their effect on the dimensional accuracy and surface quality of irreversible hydrocolloid impression materials and gypsum casts. Dent Mater. 2002;18(2):103-10.

6. Owen C, Goolam R. Disinfection of impression materials to prevent viral cross contamination: a review and a protocol. Int J Prosthodont. 1993;6(5):480-94.

7. Kumar RN, Reddy SM, Karthigeyan S, Punithavathy R, Karthik KS, Manikandan R. The effect of repeated immersion of gypsum cast in sodium hypochlorite and glutaraldehyde on its physical properties: An in vitro study. J Pharm Bioallsci 2012;4:353-7

8. Sofou A, Larsen T, Fiehn NE, Öwall B. Contamination level of alginate impressions arriving at a dental laboratory. Clin Oral Investig. 2002;6(3):161-5.

9. Tate W, Goldschmidt M, Ward M, Grant R. Disinfection and sterilization of composite polishing instruments. Am J Dent. 1995;8(5):270-2.

10. Berg E, Nielsen O, Skaug N. High-level microwave disinfection of dental gypsum casts. Int J Prosthodont. 2005;18(6):520-5.

11. Rohrer M, Bulard R. Microwave sterilization. J Am Dent Assoc. 1985;110(2):194-8.

12. Consani R, Azevedo DD, Mesquita MF, Mendes WB, Saquy PC. Effect of repeated disinfections by microwave energy on the physical and mechanical properties of denture base acrylic resins. Braz Dent J. 2009;20(2):132-7.

13. Dovigo LN, Pavarina AC, Ribeiro DG, De Oliveira JA, Vergani CE, Machado AL. Microwave disinfection of complete dentures contaminated in vitro with selected bacteria. J Prosthodont. 2009;18(7):611-7.

14. Ribeiroa DG, Pavarina AC, Dovigoa LN, Spolidorio DMP, Giampaoloa ET, Vergania CE. Denture disinfection by microwave irradiation. A randomized clinical trial. .Journal of Dentistry 2009;37:666-72

15. Sanita PV, Vergani CE, Giampaolo ET, Pavarina AC, Machado AL. Growth of Candida species on complete dentures: effect of microwave disinfection. Mycoses. 2008;52(2):154-60.

16. Berg E, Nielsen O, Skaug N. Efficacy of high-level Microwave Disinfection of Dental gypsum casts: The effects of number and weight of casts. Int J Prosthodont. 2007;20(5):463-67.

17. Abass SM, Mahmood MA, Khalaf BS. Effect of microwave irradiation on disinfection, dimensional accuracy, and surface porosity of dental casts. Med J Dent. 2011;8(2):177-187

18. Bhat V, Shenoy K, Shetty S. Evaluation of efficacy of microwave oven irradiation in disinfection of patient derived dental cast. Int J Infect Control. 2012;8(3): doi: 10.3396/ijic.v8i3.027.12.

19. Luebke R, Chan K. Effect of microwave oven drying on surface hardness of dental gypsum products. J Prosthet Dent. 1985;54(3):431-7.

20. Tuncer N. Investigation on the compressive strength of several gypsum products dried by microwave oven with different programs. Int J Prosthodont. 1993;69(3):333-9.

21. Hersek N, Canay Ş, Akça K, Çiftçi Y. Tensile strength of type IV dental stones dried in a microwave oven. J Prosthet Dent. 2002;87(5):499-502.

22. Yap A, Yap SH, Teo J, Tay C, Ng K, Thean H. Microwave drying of high strength dental stone: effects on dimensional accuracy. Oper Dent. 2003;28(2):193-9.

23. Onizuka T, Kamimura N, Kajiwara H, Nakashima A, Suenaga K, Jimi T. Influence of boiling water treatment on surface roughness and surface microstructure of set gypsum (dental stone). Dent Mater J. 1995;14(2):245-50.

24. Fredrich EG, Philip LE. Microwave sterilization of Candida on underwear fabric. A preliminary report. J Reproduct Med 1988;33(5):421-2. 
25. Tanaka Yi, Shoko Fujiwara S, Kataoka D, Takagaki T, Takano S et al. Warming and Sterilizing Towels by Microwave Irradiation. Yonago Acta medica 1998;41:83-88.

26. Najdovski L, Dragaš AZ, Kotnik V. The killing activity of microwaves on some non-sporogenic and sporogenic medically important bacterial strains. J Hosp Infect. 1991;19(4):239-47. 